\title{
Development and effectiveness of an educational program on developmental positioning for neonatal intensive care unit nurses in South Korea: a quasi-experimental study
}

\author{
Eun-Ju Yun ${ }^{1}$, Tae-Im Kim ${ }^{2}$ \\ ${ }^{1}$ Lecturer, Department of Nursing, Daejeon University, Daejeon; ${ }^{2}$ Professor, Department of Nursing, Daejeon University, Daejeon, Korea
}

Purpose: This study aimed to develop and evaluate the effectiveness of an educational program on developmental positioning (EPDP) for nurses in neonatal intensive care units (NICUs). Methods: The study utilized a non-equivalent control group pretestposttest design. Sixty NICU nurses were recruited from two university hospitals in Daejeon, South Korea. The EPDP consisted of a 7-week program: 3 weeks of education and practice, followed by 4 weeks of encouragement messages using social networking services. Developmental positioning (DP) posters and DP aids were also provided during the intervention period. The intervention group $(n=30)$ received the EPDP, but not the control group. The data were analyzed using the $x^{2}$ test, the Fisher exact test, the independent t-test, and repeated-measures analysis of variance. Results: Participants' knowledge $(\mathrm{t}=7.49, p<.001)$, attitudes $(\mathrm{t}=1.99, p=.001)$, self-efficacy $(\mathrm{t}=2.99, p=.004)$, performance of DP ( $\mathrm{t}=2.98, p=.004)$ and Infant Positioning Assessment Tool (IPAT) scores $(\mathrm{F}=29.50, p<.001)$ were significantly higher in the intervention group than in the control group. Conclusion: The EPDP can be an effective and useful program for improving the performance of DP among NICU nurses by increasing their knowledge, attitudes, and self-efficacy of DP. However, further research involving various NICU settings is needed to gather more empirical evidence.

Key words: Education; Intensive care unit, neonatal; Nurses; Patient positioning; Infants, premature

\author{
Corresponding author \\ Tae-Im Kim \\ Department of Nursing, Daejeon \\ University, 62 Daehak-ro, Dong-gu, \\ Daejeon 34520, Korea \\ TEL: +82-42-280-2654 \\ FAX: +82-42-280-2785 \\ E-MAIL: ktim56@dju.kr
}

This article was adapted from a thesis by Eun-Ju Yun in partial fulfillment of the requirements for the dissertation at Daejeon University of Korea.

Received Nov 30, 2021

Revised Dec 23, 2021

Accepted Jan 3, 2022

This is an Open Access article distributed under the terms of the Creative Commons Attribution NonCommercial License (http://creativecommons.org/licenses/by-nc/4.0/) which permits unrestricted noncommercial use, distribution, and reproduction in any medium, provided the original work is properly cited.

\section{INTRODUCTION}

The World Health Organization estimates that the proportion of preterm births ranges from $5 \%$ to $18 \%$ of babies born in 184 countries, with approximately 15 million infants being born preterm every year. In almost all countries with reliable data, preterm birth rates are increasing [1]. Premature infants are a particularly vulnerable population that requires technologically advanced medical interventions and highly specialized nursing care to survive [2-4].

Scientific and technological advancements in neonatal intensive care units (NICUs) have contributed to the increased survival of preterm neonates. However, their increased survival rate has not been accompanied by a reduction in disability rates due to the early disruption of intrauterine life and sudden exposure to an entirely unfamiliar NICU environ- ment $[2,3]$. To reduce developmental dysfunction in preterm neonates, neonatal care needs to be modified to support the neurological, social, and emotional development of neonates during hospitalization [4].

Developmental care has emerged as an effort to support the physiological stability and optimal growth and development of preterm infants while they are hospitalized in the NICU, and to minimize neuromotor disorders and complications [5-7]. Numerous approaches are used: control of external stimuli (auditory, visual, tactile) by noise and light reduction as well as minimal handling, integration of parents, specific supportive behavioral techniques such as non-nutritive sucking, opportunities for grasping, swaddling, general motor containment, kangaroo care, pain management, and developmental positioning (DP) $[3,6,8]$. DP positively induces neuromotor development in premature infants at a time of rapid 
brain development by minimizing the stress that these infants receive in the extrauterine environment and helping them to maintain a position similar to that in the mother's womb. DP is an area in which the role of NICU nurses is particularly emphasized $[2,9,10]$.

At the end of pregnancy, as the fetus grows rapidly in the mother's womb, it maintains the midline orientation, in which the head, neck, and torso are in a straight line, and physiological flexion with the arms and legs bent. These positions are the most ideal fetal postures and have the effect of improving the alignment and symmetry of joints, supporting neuromuscular development, and promoting physiological stability, self-soothing, and behavioral organization $[2,5,7,10]$. However, premature infants born without sufficient experience in the mother's womb are in a state of hypotonia because their motor subsystems are not fully developed due to their neurological immaturity. They cannot maintain their physiological flexion position through voluntary movements against gravity $[2,11]$. Therefore, if a premature infant lies in an immobile position for a long time or fails to maintain physiological flexion, the possibility of body deformation due to continued extension of the joint is very high and it is difficult to maintain physiological stability [5,12]. In addition, body deformation caused by improper posture maintenance not only interferes with the functional development of the midline orientation in premature infants, but also hinders the subsequent development of their movements such as sitting, crawling, walking and moving [3,7].

DP for preterm infants minimizes the side effects caused by improper posture maintenance, induces physiological stability in premature infants, and positively affects the development of the nervous system and musculoskeletal system $[2,3,10,11]$. NICU nurses are the medical staff who spend the longest time with premature infants while providing treatment and nursing care during their hospitalization. Therefore, NICU nurses are responsible for actively advocating and providing DP to premature infants, acquiring the professional knowledge and skills required to positively induce the developmental potential of premature infants, and applying that expertise to nursing practice [13-15]. In South Korea, nesting is applied as a part of DP in most NICUs. However, in most NICUs, positioning aids are not available, and rolled linen is used to create nests and boundaries for premature infants. DP is not provided effectively because of a lack of DP knowledge and awareness among medical staff $[13,14]$, as well as a lack of institutional support for the practical application of DP, overwork of nurses, and lack of positioning aids [14]. In addition, in-service education on DP is rarely provided except for some general hospitals, and most are provided in the form of one-time lectures, so it is difficult to apply it to nursing prac- tice [13]. Moreover, there is a lack of standardized educational programs on DP for NICU nurses. Therefore, there is a need to develop and apply a standardized and evidence-based educational program on DP (EPDP) to enhance the DP competency of nurses in the NICU.

The information-motivation-behavioral skills (IMB) model asserts that health-related information, motivation, and behavioral skills are fundamental determinants of the performance of health-related behaviors. To the extent that individuals are well informed, motivated to act, and possess the requisite behavioral skills for effective action, they are likely to initiate and maintain health-promoting behaviors, and experience positive health outcomes [16]. The IMB model has been used successfully to identify positive changes in health behavior in various patient populations [17-19] and nurses [20]. Knowledge, attitude, and self-efficacy related to developmental care nursing are known as major influencing factors that induce desirable nursing performance among NICU nurses [9,20-22]. These significant factors should be considered when designing educational programs for nurses to ensure that effective nursing care activities can be improved successfully.

The IMB model was employed here to develop and evaluate an EPDP. Furthermore, this study explored its effect on DP performance among NICU nurses.

The following hypotheses were investigated in the present study: 1) there will be a significant difference between the intervention and control groups in DP knowledge, attitudes toward DP, DP self-efficacy, and DP performance after the intervention; 2 ) the quality of DP performance will differ between the experimental and control groups after the intervention.

\section{METHODS}

Ethics statement: This study was approved by the institutional re-
view board of Daejeon Eulji Medical Center, Eulji University (No.
EMC 2018-05-001-002). Informed consent was obtained from the
participants.

\section{Research Design}

A non-equivalent control group pre-post quasi-experimental design was used.

\section{Setting}

The EPDP intervention took place in a level III NICU of a university hospital. The NICU where the EPDP intervention was provided is a 30-bed unit with approximately 200 admissions per year, of which $13 \%$ are less than 32 weeks of 
gestation. At the time of the study, there were 33 registered nurses, three NP nurses, two residents, and one neonatologist in the NICU. The NICU to which the control group belonged is also a level III NICU of a university hospital. It is a 24-bed unit with approximately 280 admissions per year, of which $11 \%$ are less than 32 weeks of gestation. At the time of the study, there were 33 registered nurses, one NP nurse, three residents, and two neonatologists in the NICU. The NICU settings of the intervention group and the control group were similar.

\section{Participants}

The participants were nurses working in the NICUs of two university hospitals (A, B) in Daejeon, South Korea. Considering the feasibility and possible cross-contamination between participants, nurses in the control and intervention groups were recruited by convenience sampling from different university hospitals. Nurses working at hospital A were assigned to the intervention group. Nurses working at hospital B were assigned to the control group. The inclusion criteria for participants were: (1) providing direct nursing care to premature infants while working in the NICU, (2) not having participated in a DP educational program for premature infants within the last 6 months, (3) having worked in the NICU for more than 6 months, and (4) understanding the purpose of this study and providing voluntary written informed consent.

The sample size was calculated using $\mathrm{G}^{*}$ Power 3.1.9. The effect size was set based on previous studies [6,8]. Based on a number of groups of 2 , a large effect size of .80 , a significance level of .05 , and a statistical power of .80 , the minimum number of samples required for testing the mean difference between two groups was 26 per group. Therefore, considering the dropout rate, a total of 61 nurses were recruited ( 31 and 30 in the intervention and control groups, respectively). One nurse in the experimental group was excluded due to a department change; finally, 30 people each from the intervention and control groups were included in the analysis.

\section{Educational Program on Developmental Positioning}

\section{1) Program development}

The IMB [16] and analysis, design, development, implementation, evaluation (ADDIE) [23] models were applied to develop the EPDP.

In the analysis phase, a literature review was conducted on DP intervention studies for nurses to construct the theme and content of the EPDP. In addition, to understand the educational needs of participants, focus group interviews were conducted with nurses with more than 5 years of work experience in the NICU. As a result, the following educational program themes were integrated into the EPDP: the difference in neurobehavioral development between intrauterine fetuses and premature infants, physiological stability and growth and development of premature infants, clues to the neurobehavioral response of premature infants, definitions and basic principles of DP, complications caused by improper posturing, the types and application of postural support assistive devices, DP methods for each position, and the advantages and disadvantages of each position.

In the design and development phase, a draft of the EPDP was constructed with the main concepts of information, motivation, and behavioral skills of the IMB model. The IMB model suggests that individuals can change and maintain their health behaviors when they acquire sufficient information, are motivated to practice healthy behaviors, and improve the behavioral skills necessary to perform healthy behaviors [16]. Therefore, these concepts were included to improve the DP performance of NICU nurses.

For the information construct, weekly group education activities were designed to enhance the participants' knowledge of DP; these activities included lectures, demonstrations, and practical training and discussions on the topics and content of the EPDP. A booklet containing educational information was provided to all participants in the intervention group.

The motivation construct was designed to induce participants' motivation for DP; in the first session, photos of incorrect postural support for premature infants were provided and the participants' thoughts and feelings were shared to draw their attention towards the severity of incorrect position support. In the second and third sessions, participants shared their experience of performing DP during the past week. In addition, personal motivation for DP performance was induced by writing a DP performance log. DP aids (e.g., gel positioning aids [Squishon 3, REP 91033-3, Philips Healthcare, New York, USA], a Bendy Bumper [Model No. 989805606731 , Philips Healthcare, New York, USA], and a baby positioning mat [Baby Positioning Mat, Akatyan No Shiro Corporation, Kurume, Japan]) were always provided in the NICU to be used for DP in premature infants. To induce participants' social motivation, they were asked to chant slogans before and after each session, and after the third session, DP encouragement messages were provided using social networking services (SNS). In addition, to encourage nurses to perform DP, posters were placed on bulletin boards in the ward and places frequently seen by nurses (NICU entrance and hand washing areas) during the intervention period.

For the behavioral skills component, the following methods were included to develop enactive mastery, vicarious experience, and verbal persuasion, all of which are sources of self- 
efficacy. These methods included DP demonstration and hands-on practice for each position using dolls and position support aids, writing a DP performance log and providing feedback, holding group discussions and sharing experiences of performing DP; providing position support aids; and chanting slogans. Active mastery of DP was induced by providing DP demonstration, practice, and feedback to enhance the participants' self-efficacy for accurate DP performance. The slogans were composed of sentences expressing the intention to pay attention to the signs of preterm infants, to strive for their development, and to perform DP. In addition, by providing a DP performance log record and feedback (verbal persuasion), the status of participants' own DP performance was discernable and their confidence in performing DP could be improved. Small-group discussions were conducted to strengthen the surrogate experience by sharing each participant's experience of performing DP. Position support aids were also provided during the intervention period to remove obstacles to DP and encourage the performance of DP.

The draft of the EPDP was verified for content validity by five experts (one professor of child health nursing, one pediatrician, one manager of the NICU, and two neonatal nurse practitioners in the NICU). The experts suggested enlarging the size of the DP photos in the booklet and presenting the advantages and disadvantages of each DP method in a comparative table to help the participants understand. Another opinion was that it would be helpful to produce and provide educational content for each session in a video to induce repeated learning. The EPDP, which was revised and supplemented in accordance with the opinions of the expert group, was conducted as a preliminary trial targeting four NICU nurses from other hospitals. Consequently, the duration of the training program was first set as 100 to 140 minutes for each session. However, it was difficult to devote 140 minutes at once because of nurses' schedule involving three shifts, but no difficulty was observed in delivering the educational content in 100 minutes. The EPDP content is shown in Table 1.

\section{2) Program implementation and effectiveness evaluation}

In the implementation and evaluation phase, three EPDP sessions were administered to the intervention group for 100 minutes a day, once a week, for 3 weeks. In addition, DP encouragement messages were provided twice a week using SNS for 4 weeks after the completion of the 3-week educational intervention, and DP aids and posters were provided throughout the intervention period. No treatment was provided to the control group, and pre- and post-test were conducted at the same time as in the intervention group.

The effectiveness of the EPDP for premature infants was measured by knowledge, attitudes, self-efficacy, and per- formance of DP before and after the provision of the educational program. The quality of DP performance was measured before and after the educational intervention, and at 4 weeks after the completion of the educational intervention (Figure $1)$.

\section{Measurements}

A structured questionnaire was used to investigate general characteristics, DP-related characteristics, IMB model constructs, and DP performance. The quality of DP performance was evaluated through structured observations using the Infant Positioning Assessment Tool (IPAT). All instruments were used with permission from the original developer.

\section{1) General and developmental positioning-related characteristics}

Data were collected from NICU nurses on general and DP-related characteristics, including age, education, marital status, NICU work experience, job status, the route of DP knowledge acquisition, the importance of DP, and barriers to implementing DP.

\section{2) Information-motivation-behavioral skills model constructs related to developmental positioning behaviors}

The Developmental Positioning Knowledge Instrument developed by Kim and Kim [14] was used to measure the level of DP knowledge. This instrument is a true-false scale with a 33-item checklist about the principles of DP, strengths and weaknesses of each position, and methods of DP. Possible scores range from 0 to 33 , with 1 point for a correct answer and 0 points for incorrect or "don't know". A higher score indicates a higher level of DP knowledge. The Kuder-Richardson 20 value of the scale was .87 , higher than the value of .75 reported by Kim and Kim [14].

The motivation construct was measured based on attitudes toward DP. Attitudes toward DP were measured using the instrument developed by Van der Pal et al.[24], and revised and supplemented into the Korean version of the Agreement with Theory of Planned Behavior Statement instrument by Lee [25]. The attitude measurement item (8-item 5-point Likert scale) was modified by the present researchers according to the purpose of the study and used after being tested for validity by experts. Possible scores range from 8 to 40, with higher scores indicating more positive attitudes toward DP. The content validity index (CVI) of the instrument was .98 , while its internal consistency (Cronbach's $\alpha$ ) was .78.

The behavioral skills construct was evaluated in terms of DP self-efficacy, which was measured using Hong's [26] Korean version of the Self-Efficacy Scale developed by Sherer et al.[27]. This 23-item 5-point Likert scale was modified ac- 
Table 1. The Content of an Educational Program on Developmental Positioning

\begin{tabular}{|c|c|c|c|}
\hline Categories & 1st Session & 2nd Session & 3rd Session \\
\hline Theme & $\begin{array}{l}\text { - Neurobehavioral development of } \\
\text { the fetus vs. preterm infants }\end{array}$ & $\begin{array}{l}\text { - Basic principles and methods of } \\
\text { DP for preterm infants }\end{array}$ & - Perform DP practice \\
\hline Goal & $\begin{array}{l}\text { - Understand and explain the } \\
\text { necessity and significance of DP } \\
\text { for preterm infants }\end{array}$ & $\begin{array}{l}\text { - Understand and explain the basic } \\
\text { principles and methods of DP for } \\
\text { preterm infants }\end{array}$ & $\begin{array}{l}\text { Participants can perform DP } \\
\text { correctly according to the situation } \\
\text { of preterm infants }\end{array}$ \\
\hline Introduction & $\begin{array}{l}\text { - Ice-breaking } \\
\text { - Introduce EPDP } \\
\text { - Show a preterm infant's case } \\
\text { photography (1): express and } \\
\text { share participant's thoughts and } \\
\text { feelings with brainwriting }\end{array}$ & $\begin{array}{l}\text { - Chanting slogans! } \\
\text { - Share participants' DP experience } \\
\text { - Introduce today's class activities }\end{array}$ & $\begin{array}{l}\text { - Chanting slogans! } \\
\text { - Share participants' DP experience } \\
\text { - Introduce today's class activities }\end{array}$ \\
\hline Development & $\begin{array}{l}\text { - Neurobehavioral development of } \\
\text { the fetus vs. preterm infants } \\
\text { - Understand the infant's cues } \\
\text { - Complications due to improper } \\
\text { positioning of preterm infants } \\
\text { - Definition and significance of DP }\end{array}$ & $\begin{array}{l}\text { - Basic principles of DP } \\
\text { - Introduce DP aids } \\
\text { - Method of DP by posture and } \\
\text { body parts of preterm infants }\end{array}$ & $\begin{array}{l}\text { - Perform and hands-on practice of } \\
\text { DP with a doll }\end{array}$ \\
\hline Ending & $\begin{array}{l}\text { - Show a preterm infant's case } \\
\text { photography (1) again: express } \\
\text { and share participants' thoughts } \\
\text { and feelings } \\
\text { - Inform participants about the next } \\
\text { class's activities } \\
\text { - Chanting slogans! }\end{array}$ & $\begin{array}{l}\text { - Show a preterm infant's case } \\
\text { photography (2): discuss with each } \\
\text { other about what's right or what's } \\
\text { wrong } \\
\text { - Inform participants about the next } \\
\text { class's activities } \\
\text { - Chanting slogans! }\end{array}$ & $\begin{array}{l}\text { - Share participants' thoughts and } \\
\text { feelings about what changed after } \\
3 \text { weeks of the EPDP } \\
\text { - Chanting slogans! }\end{array}$ \\
\hline Methods \& tools & $\begin{array}{l}\text { - Lecture, brainwriting, public } \\
\text { commitment } \\
\text { - Audio-visual materials, booklets, } \\
\text { photographs, post-it, pencils, DP } \\
\text { posters } \\
\text { - Baby positioning mat, gel } \\
\text { positioning aids, Bendy Bumper }\end{array}$ & & $\begin{array}{l}\text { - Lecture, brainwriting, public } \\
\text { commitment } \\
\text { - Hands-on practice } \\
\text { - Audio-visual materials, booklet, } \\
\text { post-it, pencil, DP posters } \\
\text { - Baby positioning mat, gel } \\
\text { positioning aids, Bendy Bumper }\end{array}$ \\
\hline IMB strategy & INF, PM, SM, BS & INF, PM, SM, BS & INF, PM, SM, BS \\
\hline Time & 100 minutes & 100 minutes & 100 minutes \\
\hline
\end{tabular}

BS, behavioral skills; DP, developmental positioning; EPDP, educational program on developmental positioning; IMB, information-motivationbehavioral skills; INF, information; PM, personal motivation; SM, social motivation.

cording to the purpose of the present study and used after validity testing by experts. Possible scores range from 23 to 115, with higher scores indicating higher self-efficacy of DP. The internal consistency (Cronbach's $\alpha$ ) of the instrument was 86 in Hong's study [26] and .85 in this study.

\section{3) Nurses' developmental positioning performance}

Nurses' DP performance was measured using the DP performance scale developed by Kim and Kim [14] and the IPAT [11]. The DP performance scale is a self-report questionnaire used to evaluate DP performance. This instrument comprises 25 items rated on a 4-point Likert scale. Possible scores range from 25 to 100; high scores indicate that the participants' performance of DP is high. The internal consistency of the instru- ment (Cronbach's $\alpha$ ) was .81 in this study. This is slightly higher than the value of .75 reported by Kim and Kim [14].

The quality of nurses' DP performance was measured using the IPAT developed by Coughlin et al.[11]. The IPAT is a pictorial tool demonstrating optimal DP in six areas of the body (head, chin/neck, shoulders, hands/arms, pelvis, and knees/ ankles/feet). Each area of the body is scored 0 to 2, with cumulative scores ranging from 0 to 12: a score of 2 indicates appropriate positioning, 1 corresponds to acceptable alternative positioning, and 0 indicates unacceptable positioning. A full score of 12 is interpreted as perfect positioning, a score of 9-12 is acceptable, and a score of 8 or lower indicates the need for repositioning. A higher score corresponds to better DP performance of NICU nurses. The content validity and reliability 


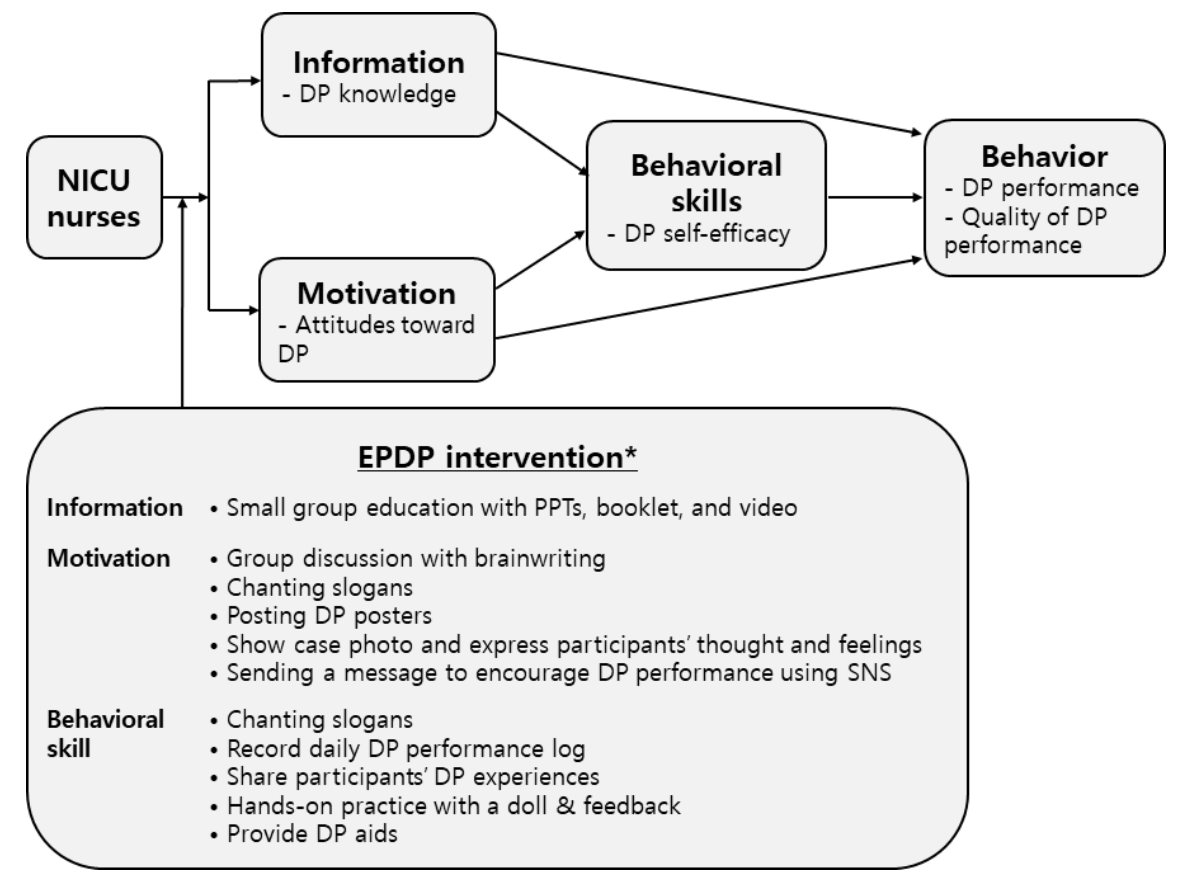

Figure 1. The conceptual framework of the research. ${ }^{*}$ The EPDP was conducted for 7 weeks ( 3 session of education and practice for three weeks; encouraging DP messages using SNS were provided for four weeks after three sessions of DP education and practice; DP posters and DP aids were provided during the intervention periods). DP, developmental positioning; EPDP, educational program on developmental positioning; NICU, neonatal intensive care unit; PPT, PowerPoint; SNS, social network service.

of this tool have been established in previous studies $[2,9,11$, $22,28]$.

\section{Preparing Researchers and Research Assistants}

The primary investigator has completed a doctoral program in nursing and has worked for 20 years as a neonatal nurse practitioner in the NICU at a university hospital. In the doctoral program, she took six credits of developmental care courses, and had participated in four workshops on developmental care.

The four research assistants were nurses with more than 10 years of work experience in the NICU who had masters' degrees. Before data collection, they received 4 hours of training from the investigator on the principles and methods of DP for premature infants, as well as the principles and practices of IPAT evaluation. In addition, for IPAT evaluation, inter-observer rating training education was conducted and data collection was carried out after the degree of agreement between observers reached .95 or more.

\section{Data Collection}

The research process was carried out from February 28, 2019 to April 30, 2019.

\section{1) Pre-test}

After the researcher explained the purpose and details of the program, and obtained written consent from participants for the research, the research assistants distributed the questionnaire and conducted a pre-test before the intervention. Using a questionnaire, data were collected from both experimental and control groups on general and DP-related characteristics, DP knowledge, attitudes toward DP, DP self-efficacy, and DP performance. The survey took 15-20 minutes to administer. IPAT evaluation was performed by two research assistants at $7 \mathrm{AM}, 2 \mathrm{PM}$, and $9 \mathrm{PM}$ in the NICU at each university hospital.

\section{2) Intervention}

The intervention was conducted for 7 weeks. The intervention group received 300 minutes of DP education and practice for 3 weeks. After three sessions of DP education and practice, encouragement messages using SNS were provided for 4 weeks. During the intervention period, DP posters were displayed and DP aids were provided. Each session of DP education and practice was conducted twice a day (11:30 AM, 4:30 PM) in consideration of the three-shift work schedule of the intervention group. For the experimental group, EPDP education and practice were conducted, and the booklet and video developed by the researcher were also provided. The 
control group did not receive the EPDP intervention during the study period, although the EPDP booklet and video were provided after the study was over.

\section{3) Post-test}

Post-tests were conducted for the experimental and control groups after the educational program was completed. A self-report questionnaire was used to evaluate DP knowledge, attitudes toward DP, DP self-efficacy, and DP performance. In addition, four research assistants evaluated the degree of DP performance using IPAT. The IPAT scoring was conducted again 4 weeks after completion of the educational program.

\section{Ethical Considerations}

After approval by the institutional review board (No. EMC 2018-05-001-002) of the Daejeon Eulji Medical Center, Eulji University. Participants were recruited from two university hospitals, provided with detailed information about the study and informed that they could withdraw from the study at any time. Informed consent was obtained prior to data collection. After the intervention, the participants in the control group were given a booklet and video containing information about DP.

\section{Data Analysis}

Data were analyzed using SPSS version 22.0 for Windows (IBM Corp., Armonk, NY, USA). Participants' general and DP-related characteristics were analyzed with descriptive statistics such as frequency, percentage, mean, and standard deviation. The normality of the dependent variables was examined using the Kolmogorov-Smirnov test. The results showed that all quantitative variables were normally distributed. Homogeneity testing was conducted using the $x^{2}$ test, the Fisher exact test, and the independent t-test for the characteristics and variables in the intervention and control groups. The differences in the post-test variables between the two groups were examined using the independent $t$-test. Changes in the IPAT score in the intervention and control groups were analyzed by repeated-measures analysis of variance.

\section{RESULTS}

\section{Participants' Characteristics}

The mean age of the participants was 27.2 years, most had a bachelor's degree or higher $(86.7 \%)$, and $85.0 \%$ were married. Participants' mean NICU work experience was 49.4 months, and most were staff nurses (91.7\%). The routes of DP knowl- edge acquisition of the participants were in-service education $(34.0 \%)$, the internet $(30.2 \%)$, clinical conferences $(11.3 \%)$, books $(9.4 \%)$, and senior nurses $(9.4 \%)$. The importance of DP perceived by the participants was measured by a single-item 5 -point scale, which yielded a score of 4.28 out of 5.00. The barriers implementing DP were work overload $(35.0 \%)$, lack of awareness of DP (20.0\%), lack of DP education (18.3\%), lack of position support aids $(11.7 \%)$, concerns about missing tubes and lines $(8.3 \%)$, and inadequate staffing $(6.7 \%)$. There were no significant differences between the intervention and control groups regarding the general and DP-related characteristics at baseline (Table 2).

\section{Test of Baseline Homogeneity of Variables between Groups}

Homogeneity testing showed that there were no statistically significant differences between the intervention and control groups in the following outcome variables at baseline: the level of knowledge, attitudes, and self-efficacy related to DP; DP performance; and IPAT scores (Table 2).

\section{Hypothesis Testing}

The differences of post-test outcome variables are presented in Table 3. The intervention group showed a higher DP knowledge score than the control group, and the difference was statistically significant $(t=7.49, p<.001)$. Regarding the motivation construct, the intervention group showed a higher level of attitudes toward DP score than the control group and the difference was statistically significant $(\mathrm{t}=1.99, p=.005)$. The intervention group showed a significantly higher DP self-efficacy score than the control group $(\mathrm{t}=2.99, p=.004)$. The intervention group showed a significantly higher DP performance score than the control group $(t=2.98, p=.004)$. The IPAT scores of the experimental and control groups showed statistically significant differences over time $(\mathrm{F}=48.40, p<.001)$, and there was a statistically significant interaction according to time-by-group $(\mathrm{F}=29.50, p<.001)$ (Table 4$)$.

\section{DISCUSSION}

We evaluated the effectiveness of an IMB model-based EPDP for NICU nurses with the aim of providing an empirical basis for the diffusion of EPDP. The results indicate that the theoretically grounded EPDP significantly increased knowledge, attitudes, self-efficacy, DP performance, and IPAT scores. This suggests that NICU nurses' performance of DP improved by providing information on $\mathrm{DP}$, inducing personal and social motivation, and improving behavioral skills, which 
Table 2. Homogeneity Tests of the General and DP-related Characteristics of the Participants and Outcome Variables of the Two Groups at Baseline $(N=60)$

\begin{tabular}{|c|c|c|c|c|c|c|}
\hline \multirow[b]{2}{*}{ Variables } & \multirow[b]{2}{*}{ Categories } & Total $(N=60)$ & Int. $(n=30)$ & Cont. $(n=30)$ & \multirow[b]{2}{*}{$x^{2}$ or $\mathrm{t}$} & \multirow[b]{2}{*}{$p$} \\
\hline & & $\begin{array}{l}\mathrm{n}(\%) \text { or } \\
\mathrm{M} \pm \mathrm{SD}\end{array}$ & $\begin{array}{l}\mathrm{n}(\%) \text { or } \\
\mathrm{M} \pm \mathrm{SD}\end{array}$ & $\begin{array}{l}\mathrm{n}(\%) \text { or } \\
\mathrm{M} \pm \mathrm{SD}\end{array}$ & & \\
\hline Age (year) & $\begin{array}{l}\leq 25 \\
26-30 \\
\geq 31\end{array}$ & $\begin{array}{l}33(55.0) \\
14(23.3) \\
13(21.7) \\
27.2 \pm 5.2\end{array}$ & $\begin{array}{r}18(60.0) \\
5(16.7) \\
7(23.3) \\
26.9 \pm 5.0\end{array}$ & $\begin{array}{r}15(50.0) \\
9(30.0) \\
6(20.0) \\
27.5 \pm 5.5\end{array}$ & $\begin{array}{l}1.49 \\
0.42\end{array}$ & $\begin{array}{l}.474 \\
.676\end{array}$ \\
\hline Education & $\begin{array}{l}\text { Junior college } \\
\geq \text { University }\end{array}$ & $\begin{array}{r}8(13.3) \\
52(86.7)\end{array}$ & $\begin{array}{r}4(13.3) \\
26(86.7)\end{array}$ & $\begin{array}{r}4(13.3) \\
26(86.7)\end{array}$ & & $.710^{*}$ \\
\hline Marital status & $\begin{array}{l}\text { Married } \\
\text { Unmarried }\end{array}$ & $\begin{array}{r}9(15.0) \\
51(85.0)\end{array}$ & $\begin{array}{l}3(10.0) \\
27(90.0)\end{array}$ & $\begin{array}{c}6(20.0) \\
24(80.0)\end{array}$ & 1.08 & .282 \\
\hline $\begin{array}{l}\text { NICU work experience } \\
\text { (month) }\end{array}$ & $\begin{array}{l}<24 \\
25-48 \\
\geq 49\end{array}$ & $\begin{array}{c}31(51.7) \\
15(25.0) \\
14(23.3) \\
49.4 \pm 45.8\end{array}$ & $\begin{array}{c}18(60.0) \\
5(16.7) \\
7(23.3) \\
45.0 \pm 43.0\end{array}$ & $\begin{array}{c}13(43.4) \\
10(33.3) \\
7(23.3) \\
53.8 \pm 48.7\end{array}$ & 2.47 & $\begin{array}{l}.290 \\
.975\end{array}$ \\
\hline Job status & $\begin{array}{l}\text { Staff nurse } \\
\geq \text { Charge nurse }\end{array}$ & $\begin{array}{c}55(91.7) \\
5(8.3)\end{array}$ & $\begin{array}{r}27(90.0) \\
3(10.0)\end{array}$ & $\begin{array}{c}28(93.4) \\
2(6.6)\end{array}$ & & $.098^{*}$ \\
\hline $\begin{array}{l}\text { Route of DP knowledge } \\
\text { acquisition }^{\dagger}\end{array}$ & $\begin{array}{l}\text { In-service education } \\
\text { Internet } \\
\text { Clinical conference } \\
\text { Books } \\
\text { Senior nurse } \\
\text { None }\end{array}$ & $\begin{aligned} 18 & (34.0) \\
16 & (30.2) \\
6 & (11.3) \\
5 & (9.4) \\
5 & (9.4) \\
3 & (5.7)\end{aligned}$ & $\begin{array}{l}7(25.9) \\
9(33.4) \\
2(7.4) \\
3(11.1) \\
3(11.1) \\
3(11.1)\end{array}$ & $\begin{aligned} 11 & (42.3) \\
7 & (26.9) \\
4 & (15.4) \\
2 & (7.7) \\
2 & (7.7) \\
0 & (0.0)\end{aligned}$ & - & - \\
\hline Importance of DP & & $4.28 \pm 0.55$ & $4.20 \pm 0.48$ & $4.37 \pm 0.62$ & 1.17 & .248 \\
\hline $\begin{array}{l}\text { Barriers to } \\
\text { implementing DP }\end{array}$ & $\begin{array}{l}\text { Work overload } \\
\text { Lack of awareness of DP } \\
\text { Lack of DP education } \\
\text { Lack of position support aids } \\
\text { Concerns about missing tubes and lines } \\
\text { Inadequate staffing }\end{array}$ & $\begin{aligned} 21 & (35.0) \\
12 & (20.0) \\
11 & (18.3) \\
7 & (11.7) \\
5 & (8.3) \\
4 & (6.7)\end{aligned}$ & $\begin{array}{r}13(43.3) \\
6(20.0) \\
7(23.3) \\
2(6.7) \\
2(6.7) \\
0(0.0)\end{array}$ & $\begin{array}{l}8(26.7) \\
6(20.0) \\
4(13.3) \\
5(16.7) \\
3(10.0) \\
4(13.3)\end{array}$ & - & - \\
\hline DP knowledge & & $24.15 \pm 3.52$ & $24.20 \pm 3.75$ & $24.10 \pm 3.90$ & 0.10 & .920 \\
\hline Attitudes towards DP & & $29.53 \pm 3.48$ & $29.40 \pm 2.77$ & $29.66 \pm 4.11$ & 2.29 & .770 \\
\hline DP self-efficacy & & $75.58 \pm 7.94$ & $77.26 \pm 7.96$ & $73.90 \pm 7.68$ & 1.67 & .101 \\
\hline DP performance & & $76.38 \pm 6.86$ & $75.20 \pm 6.17$ & $77.56 \pm 7.39$ & 1.35 & .184 \\
\hline IPAT score & & $5.08 \pm 1.63$ & $5.07 \pm 1.58$ & $5.10 \pm 1.70$ & 0.08 & .938 \\
\hline
\end{tabular}

${ }^{*}$ Fisher exact test; ${ }^{\dagger}$ Non-responders were excluded from the analysis; Cont., control group; DP, developmental positioning; Int., intervention group; IPAT, Infant Positioning Assessment Tool.

Table 3. Effects of the Educational Program on Developmental Positioning $(N=60)$

\begin{tabular}{|c|c|c|c|c|}
\hline \multirow{2}{*}{ Variables } & Int. $(n=30)$ & Cont. $(n=30)$ & \multirow{2}{*}{$t$} & \multirow{2}{*}{$p$} \\
\hline & $\mathrm{M} \pm \mathrm{SD}$ & $\mathrm{M} \pm \mathrm{SD}$ & & \\
\hline DP knowledge & $29.73 \pm 1.80$ & $24.57 \pm 3.32$ & 7.49 & $<.001$ \\
\hline Attitudes toward DP & $32.43 \pm 3.02$ & $31.03 \pm 2.37$ & 1.99 & .005 \\
\hline DP self-efficacy & $83.86 \pm 12.60$ & $75.30 \pm 9.31$ & 2.99 & .004 \\
\hline DP performance & $84.56 \pm 7.68$ & $78.33 \pm 7.43$ & 2.98 & .004 \\
\hline
\end{tabular}

Cont., control group; DP, developmental positioning; Int., intervention group. 
Table 4. Infant Positioning Assessment Tool (IPAT) Score Change between Groups $(N=60)$

\begin{tabular}{|c|c|c|c|c|c|c|c|c|}
\hline \multirow{3}{*}{ Variable } & \multirow{3}{*}{ Groups } & \multicolumn{3}{|c|}{ Time } & \multirow{3}{*}{ Source } & \multirow{3}{*}{$\mathrm{F}$} & \multirow{3}{*}{$p$} & \multirow{3}{*}{ Post-hoc ${ }^{\dagger}$} \\
\hline & & Pretest & Posttest $1^{*}$ & Posttest $2^{\dagger}$ & & & & \\
\hline & & $\mathrm{M} \pm \mathrm{SD}$ & $\mathrm{M} \pm \mathrm{SD}$ & $\mathrm{M} \pm \mathrm{SD}$ & & & & \\
\hline IPAT score & $\begin{array}{l}\text { Int. }(n=30) \\
\text { Cont. }(n=30)\end{array}$ & $\begin{array}{l}5.07 \pm 1.58^{\mathrm{a}} \\
5.10 \pm 1.70\end{array}$ & $\begin{array}{l}5.47 \pm 1.76^{\mathrm{b}} \\
5.23 \pm 1.50\end{array}$ & $\begin{array}{l}6.80 \pm 2.07^{c} \\
5.37 \pm 1.59\end{array}$ & $\begin{array}{c}\text { Group } \\
\text { Time } \\
G^{*} \mathrm{~T}\end{array}$ & $\begin{array}{r}1.63 \\
48.40 \\
29.50\end{array}$ & $\begin{array}{r}.207 \\
<.001 \\
<.001\end{array}$ & $\begin{array}{c}\mathrm{a}<\mathrm{b}, \mathrm{c} \\
\mathrm{b}<\mathrm{c}\end{array}$ \\
\hline
\end{tabular}

${ }^{*}$ After intervention; ${ }^{\dagger} 4$ weeks after intervention; ${ }^{\dagger}$ Tukey's HSD test, $p<.050$; Cont., control group; G*T, group by time; Int., intervention group; IPAT, Infant Positioning Assessment Tool.

are components of the IMB model. In particular, the differentiated intervention strategies applied in the EPDP developed in this study to transfer information and enhance motivation and behavioral skills based on the IMB model are as follows.

First, educational topics were systematically constructed based on a literature review, DP guidelines, and the results of a needs assessment among NICU nurses. The educational media developed included PowerPoint presentations (PPTs), booklets, and videos. To induce learning motivation, empathy, and positive attitude change in participants, PPTs and booklets were mainly composed of drawings and photos [20]. Furthermore, the media were developed as educational videos so that participants could use them at any time [2,8]. Educational strategies such as lectures, small group discussions, and experiential activities were used to enhance the participants' learning $[8,28,29]$. We believe that it was possible to improve the DP knowledge of the participants in the intervention group. These arguments are consistent with evidence from previous studies $[8,9,21,30]$.

Second, personal motivation was induced by sharing feelings using various postural photos of premature infants. In order to encourage participants' active participation, they were divided into small groups of 4 to 5 and shared their thoughts and feelings on DP using the brainwriting technique. Personal motivation was induced by providing an opportunity for self-evaluation of DP performance by writing and checking the daily DP performance log. In this study, the daily DP performance log was collected and analyzed on a weekly basis, and the results were reflected in the education session, explained, and practiced. If necessary, bedside feedback with hands-on correction of positioning was provided to the participants. Although it was not possible to provide daily feedback and correction of positioning due to on-site circumstances, it is thought that nurses were able to induce their motivation for DP by observing the immediate benefits of DP [9]. To develop social motivation, DP posters were attached to encourage the performance of DP in the NICU; furthermore, encouraging messages were provided using SNS. Posters are an effective medium for delivering messages to achieve educa- tional goals, which can arouse participants' attention and interest [4]. In our opinion, it was possible to improve the attitudes toward DP in the intervention group by applying these intervention strategies. These findings are similar to those reported by Milette et al.[30], who found that NICU nurses who received developmental care training showed improvements in attitudes, intention, and behaviors of developmental care. The results suggest that the EPDP was effective in positively influencing attitudes toward DP in the intervention group.

Third, regarding behavioral skills, slogans were chanted as a way to use the public declaration effect to enhance participants' motivation and self-efficacy [20]. Furthermore, surrogate experience was induced by sharing each other's successful experiences of performing DP [17]. In addition, participants undertook DP practice using a doll and an auxiliary device for DP. The IMB model emphasizes self-efficacy and suggests that when subjects have confidence in their own abilities, this is expressed in their behaviors, and they continue to engage in the behavior despite various obstacles [16]. This suggests that there is a close relationship between self-efficacy and performing specific behaviors. Here, we considered that the self-efficacy of the intervention group was significantly increased by chanting slogans, sharing experiences of DP, writing and checking a DP performance log, and practicing DP as strategies for improving self-efficacy. Previous studies have also applied noise reduction intervention programs for NICU nurses to improve their performance [20]. In addition, DP aids were provided to minimize obstacles to DP. Commercialized DP aids are easier to separate and assemble than rolled linen, making it possible to support DP for even a premature infant with many lines without much difficulty. In addition, in cases of premature infants for whom position support was difficult, the primary investigator provided additional demonstrations and feedback to the nurses at the bedside. Thus, by using various educational strategies to reinforce the basic assumptions of the IMB model, after the intervention, the intervention group's knowledge, attitudes, self-efficacy, DP performance, and IPAT score improved.

After the EPDP intervention, the DP performance and IPAT scores of the experimental group were significantly higher 
than those of the control group. This suggests that the EPDP developed by the research team was an effective intervention strategy to improve DP performance among nurses. According to the IMB model, health-related information, motivation, and behavioral skills are fundamental determinants of the performance of health-related behaviors [16]. In this study, scores for DP knowledge, attitudes toward DP, and DP self-efficacy were higher in the intervention group than in the control group, so it is thought that their DP performance could be improved. This result is consistent with the results of previous studies that educating nurses on DP is effective in enhancing their DP performance $[2,22,28-30]$. However, the previous studies were conducted as field studies $[2,9,29,30]$ or quality improvement projects $[22,28]$, making it difficult to provide consistent interventions due to the long intervention period, and there was a limitation in identifying the pure effect of the educational program on DP using a one-group pre-and posttest design. In contrast, this study is meaningful in that it improved the explanatory power of the program's effects by systematically developing an EPDP program based on the IMB model and verifying it using a non-equivalent control group pre-and post-test design. However, considering that periodic ongoing education on DP provision is effective in enhancing nurses' DP performance [29], a follow-up study is needed to determine the long-term effect of the EPDP.

In this study, compared with the control group, the intervention group showed significantly higher IPAT scores after intervention. This finding is supported by previous studies that reported significant improvements in mean IPAT scores after an intervention $[2,9,22,28]$. The IPAT is generally accepted as a reliable measure of the quality of infant positioning $[9,11,22,28]$. Our study results indicate that EPDP improved the quality of DP among nurses, which is ultimately expected to be effective in inducing positive developmental outcomes in premature infants. Therefore, we suggest the need for follow-up studies on the effects of EPDP on the developmental outcomes of premature infants. A study by Perkins et al.[29] reported that nurses' abilities to position neonates in developmentally supportive positions after nursing education on DP improved; however, improvements declined in the absence of ongoing education. This was also found in another previous study [4]. These results are inconsistent with the findings of the present study. Although the intervention period of our study was not long, it is considered that the delivery of encouraging DP messages using SNS for 4 weeks had an effect on maintaining the continuity of the intervention effect. In the studies of Charafeddine et al.[28] and Jeanson [9], who provided periodic ongoing education on DP with bedside hands-on demonstration and feedback, the IPAT score increased. Considering this, periodic education on DP with bedside hands-on demonstration and feedback, as well as the delivery of encouraging DP messages using SNS by the researchers, can be interpreted as increasing the IPAT score. A follow-up study is needed to confirm this.

Although the IPAT scores of the experimental group increased significantly after the EPDP intervention, the IPAT score was 5.47 and 6.80 at post-test 1 and post-test 2, respectively; thus, it did not reach the optimal score of 9 and above. A score of 8 or less indicates a need for correction and adjustment of positioning $[9,11]$. Other studies [22,28], have reported higher IPAT scores after a DP intervention. In these studies, the DP intervention was conducted as part of a quality improvement program, which provided institutional support from hospitals and induced engagement of medical personnel, including nurses and pediatric residents, in educational programs. The intervention period was 6-28 months. In contrast, in this study, only nurses were targeted. Therefore, it was not possible to elicit the cooperation of medical personnel, there was no support from the hospital to encourage the performance of DP, and the intervention period was as short as 7 weeks. These differences may explain why IPAT scores did not increase further and were lower than those reported in previous studies $[4,8,21,22,28,29]$. Furthermore, the priority of DP may have been reduced due to an excessive workload $[21,22]$. This study's results show that $35 \%$ of nurses were unable to perform DP due to an excessive workload, although they recognized the importance of DP. Therefore, these factors may have acted as barriers to performing DP. Future research can verify the effects of various factors on DP performance, including the nurse-to-patient ratio, hospital policy support, the inclusion of residents in educational programs, and the intervention period.

This study has some limitations. First, there may have been selection bias since it was not feasible to use a randomized design with random allocation, and there was a possible risk of contamination. Second, the IPAT evaluation over three rounds did not target the same premature infants. Third, due to ethical considerations, the participants could not be blinded to the data collection in this study; this may have affected the research results. Lastly, because of the circumstances of the hospital during the coronavirus disease 2019 pandemic, after the 7-week EPDP intervention was completed, it was not possible to confirm the changes of variables over time except for IPAT scores. Therefore, the interpretation of the results of this study may not be generalizable to all NICU nurses.

However, to the best of our knowledge, this is the first experimental study to evaluate an IMB model-based intervention that targeted NICU nurses to promote their DP proficiency. Therefore, this study is meaningful in that it presents evidence to support the dissemination of improvements 
in nursing practice by developing the EPDP and verifying its effectiveness. Furthermore, this study provides empirical evidence for the theoretical assumptions of the IMB model.

\section{CONCLUSION}

In this study, the IMB model was used to develop and evaluate an EPDP to improve the DP performance of NICU nurses. The EPDP improved the IPAT scores and the knowledge, attitude, self-efficacy, and performance of DP among NICU nurses.

In the future, it is expected that empirical evidence will be gathered through repeated studies applying the EPDP and that the EPDP will be widely used in nursing practice, contributing to the positive growth and development of preterm infants. Further research could include a randomized control group study to investigate the pure effect of EPDP; furthermore, a longitudinal study could be undertaken to determine the effect of the EPDP on the physiological stability of premature infants.

\section{ORCID}

Eun-Ju Yun

https://orcid.org/0000-0003-0934-3838

Tae-Im Kim

https://orcid.org/0000-0002-2603-4597

\section{Authors' contribution}

Conceptualization: all authors; Data collection, Formal analysis: Eun-Ju Yun; Writing-original draft, Writing-review and editing: all authors; Final approval of published version: all authors.

\section{Conflict of interest}

No existing or potential conflict of interest relevant to this article was reported.

\section{Funding}

None.

\section{Data availability}

Please contact the corresponding author for data availability.

\section{Acknowledgements}

None.

\section{REFERENCES}

1. World Health Organization. Preterm birth [Internet]. World Health Organization; 2021 [cited 2021 November 10]. Available from:

https://www.who.int/en/news-room/fact-sheets/detail/preter m-birth

2. Spilker A, Hill C, Rosenblum R. The effectiveness of a standardized positioning tool and bedside education on the developmental positioning proficiency of NICU nurses. Intensive and Critical Care Nursing. 2016;35:10-15.

https://doi.org/10.1016/j.iccn.2016.01.004

3. Montirosso R, Tronick E, Borgatti R. Promoting neuroprotective care in neonatal intensive care units and preterm infant development: insights from the neonatal adequate care for quality of life study. Child Development Perspectives. 2017;11(1):9-15. https://doi.org/10.1111/cdep.12208

4. Mohammed RE, Khamis GM, Sabry YY. Effect of preterm neonates' developmental supportive care program on nurses' performance. IOSR Journal of Nursing and Health Science. 2018;7(4): 33-45. https://doi.org/10.9790/1959-0704053345

5. Als H. Toward a synactive theory of development: promise for the assessment and support of infant individuality. Infant Mental Health Journal. 1982;3(4):229-243.

https://doi.org/10.1002/1097-0355(198224)3:4<229::AID-IMHJ2 $280030405>3.0 . \mathrm{CO} ; 2-\mathrm{H}$

6. Altimier L, Kenner C, Damus K. The wee care neuroprotective NICU program (Wee Care): the effect of a comprehensive developmental care training program on seven neuroprotective core measures for family-centered developmental care of premature neonates. Newborn and Infant Nursing Reviews. 2015;15(1):6-16. https://doi.org/10.1053/j.nainr.2015.01.006

7. Valizadeh L, Asadollahi M, Gharebaghi MM, Gholami F. The congruence of nurses' performance with developmental care standards in neonatal intensive care units. Journal of Caring Sciences. 2013;2(1):61. https://doi.org/10.5681/jcs.2013.008

8. Mohammed SA, Bayoumi MH, Mahmoud FS. The effect of developmentally supportive care training program on nurses' performance and behavioral responses of newborn infants. Journal of Education and Practice. 2014;5(6):134-144.

9. Jeanson E. One-to-one bedside nurse education as a means to improve positioning consistency. Newborn and Infant Nursing Reviews. 2013;13(1):27-30. https://doi.org/10.1053/j.nainr.2012.12.004

10. Waitzman KA. The importance of positioning the near-term infant for sleep, play, and development. Newborn and Infant Nursing Reviews. 2007;7(2):76-81. https://doi.org/10.1053/j.nainr.2007.05.004

11. Coughlin M, Lohman MB, Gibbins S. Reliability and effectiveness of an infant positioning assessment tool to standardize developmentally supportive positioning practices in the neonatal in- 
tensive care unit. Newborn and Infant Nursing Reviews. 2010;10 (2):104-106. https://doi.org/10.1053/j.nainr.2010.03.003

12. Nuysink J, Van Haastert IC, Eijsermans MJ, Koopman-Esseboom C, Van der Net J, De Vries LS, et al. Prevalence and predictors of idiopathic asymmetry in infants born preterm. Early Human Development. 2012;88(6):387-392.

https://doi.org/10.1016/j.earlhumdev.2011.10.001

13. Kim JS, Shin HS. Concept analysis of developmental care for preterm infants: hybrid model. Child Health Nursing Research. 2014; 20(4):350-358. https://doi.org/10.4094/chnr.2014.20.4.350

14. Kim MJ, Kim TI. Knowledge and performance of developmentally supportive positioning for premature infants among neonatal intensive care unit nurses. Child Health Nursing Research. 2018;24 (2):229-240. https://doi.org/10.4094/chnr.2018.24.2.229

15. Purdy IB, Melwak MA, Smith JR, Kenner C, Chuffo-Siewert R, Ryan DJ, et al. Neonatal nurses NICU quality improvement. Advances in Neonatal Care. 2017;17(1):33-44. https://doi.org/10.1097/ANC.0000000000000352

16. Fisher JD, Fisher WA. Changing AIDS-risk behavior. Psychological Bulletin. 1992;111(3):455-474. https://doi.org/10.1037/0033-2909.111.3.455

17. Lee MH, Park YH. The effectiveness of the information-motivation -behavioral skills model-based intervention on preventive behaviors against respiratory infection among community-dwelling older adults. Patient Education and Counseling. 2021;104(8):2028-2036. https://doi.org/10.1016/j.pec.2021.01.016

18. Wells A, Allen-Brown V, Alam N, Skulski C, Jackson AL, Herzog TJ. The importance of information, motivation, and behavioral skills (IMB): health care provider perspectives on improving adherence to cervical cancer screening among at-risk women. Public Health in Practice. 2021;2:100079. https://doi.org/10.1016/j.puhip.2021.100079

19. Kim JS, Kim CJ. Effect of a physical activity promoting program based on the IMB model on obese-metabolic health outcomes among obese older adults with knee osteoarthritis. Journal of Korean Academy of Nursing. 2020;50(2):271-285. https:// doi.org/10.4040/jkan.2020

20. Lee SA. Development and evaluation of NICU noise management program [Master's thesis]. Daejeon: Daejeon University; 2019. p. $1-112$.

21. Hasanpour M, Farashi F, Mohammadizadeh M, Abdeyazdan Z.
The impact of a neonatal sleep care training program on nurses' knowledge and performance in neonatal intensive care units. Iranian Journal of Nursing and Midwifery Research. 2017;22(3): 215-218. https://doi.org/10.4103/1735-9066.208159

22. Masri S, Ibrahim P, Badin D, Khalil S, Charafeddine L. Structured educational intervention leads to better infant positioning in the NICU. Neonatal Network. 2018;37(2):70-77.

https://doi.org/10.1891/0730-0832.37.2.70

23. Richey RC, Seels BB. Defining a field: a case study of the development of the 1994 definition of instructional technology. Educational Media and Technology Yearbook. 1994;20:2-17.

24. Van der Pal SM, Maguire CM, Le Cessie S, Veen S, Wit JM, Walther FJ, et al. Staff opinions regarding the newborn individualized developmental care and assessment program (NIDCAP). Early Human Development. 2007;83(7):425-432.

https://doi.org/10.1016/j.earlhumdev.2007.03.007

25. Lee SJ. Predictors of developmental supportive care in neonatal intensive care unit nurses [master's thesis]. Seoul: Hanyang University; 2017. p. 1-68.

26. Hong HY. The relationship of perfectionism, self-efficacy and depression [master's thesis]. Seoul: Ewha Womans University; 1995. p. 1-73.

27. Sherer M, Maddux JE, Mercandante B, Prentice-Dunn S, Jacobs B, Rogers RW. The self-efficacy scale: Construction and validation. Psychological Reports. 1982;51(2):663-671.

https://doi.org/10.2466/pr0.1982.51.2.663

28. Charafeddine L, Masri S, Ibrahim P, Badin D, Cheayto S, Tamim H. Targeted educational program improves infant positioning practice in the NICU. International Journal for Quality in Health Care. 2018;30(8):642-648. https://doi.org/10.1093/intqhc/mzy123

29. Perkins E, Ginn L, Fanning JK, Bartlett DJ. Effect of nursing education on positioning of infants in the neonatal intensive care unit. Pediatric Physical Therapy. 2004;16(1):2-12. https:// doi.org/10.1097/01.PEP.0000112916.38869.5E

30. Milette I, Martel MJ, Da Silva MR, McNeil MC. Guidelines for the institutional implementation of developmental neuroprotective care in the neonatal intensive care unit. Part A: background and rationale. A joint position statement from the CANN, CAPWHN, NANN, and COINN. Canadian Journal of Nursing Research. 2017;49(2):46-62. https://doi.org/10.1177/0844562117706882 